\title{
Filosofar científicamente y encarar la ciencia filosóficamente*
}

\author{
Mario Bunge \\ Universidad de McCill (Montreal)
}

\section{El lugar de la epistemología en la universidad argentina}

Es fácil advertir cuán modesto es el lugar que actualmente ocupa la filosofía de la ciencia en nuestras universidades. Si se exceptúan los pintorescos cursos de "epistemología de la ingeniería" de años recientes, la filosofía de la ciencia se enseña solamente en las facultades de filosofía, y en éstas no ocupa un lugar importante. ¿Qué importancia puede dársele a uno de los pocos cursos de filosofía sistemática que figuran en un plan de estudios que parece confeccionado a la medida de especialistas en filosofía grecorromana y medieval?, ¿qué importancia puede tener un único curso de filosofía de la ciencia, comparado con todos los cursos de filosofía y de lenguas muertas? Es una de tantas materias, acaso la más humilde de todas.

Tan poca importancia se le asigna a la filosofía de la ciencia en nuestra universidad, que el estudiante es lanzado a ella inerme. No se le dota, por ejemplo, de nociones científicas de nivel universitario; no se le equipa con las herramientas de la lógica moderna y del análisis lógico del lenguaje; del alemán y del francés. Es claro que a menudo se hallaba consuelo en la circunstancia de que tampoco se exigían estos requisitos elementales a quienes enseñaban la materia o simulaban hacerlo.

La filosofía de la ciencia está arrinconada en el plan de estudios y, en general, en el panorama filosófico del país. Entre nosotros no se considera deseable que el filósofo se inspire en el modo del proceder científico, quien comienza por los hechos, luego los describe y más tarde fórmula hipótesis y

* Clase inaugural del curso de Filosofia de la Ciencia en la Facultad de Filosofia y Letras, Buenos Aires, 5 de abril de 1957. Reproducimos el texto publicado en: Proceso. Revista de la Federación de Estudiantes d ela Universidad Agraria La Molina (Lima). No 1. 1968-1969, pp. $24-32$.

LETRAS (Lima), 94: 69-84,1997. 
construye teorías para explicarlos; después deduce de ellas conclusiones particulares verificables, recurre eventualmente a nuevas observaciones o a nucvos cálculos y contrasta sus conclusiones con estos resultados; y finalmente, si lo halla necesario, corrige sus conjeturas sin compasión. Este severo carácter autocorrectivo de la investigación científica tradicional, la que siempre titubeaba en formular conjeturas sin fundamento y sin verificación.

Entre nosotros apenas se considera interesante la riquísima problemática filosófica que suscita la ciencia; para algunos, dicha problemática es demasiado estrecha, para otros demasiado árida, y para la mayoría de los filósofos y científicos ella apenas existe: se cree vulgarmente, en efecto, que la ciencia carece de problemas filosóficas y que no es más que una máquina de buscar datos. Entre nosotros suele encontrarse más cómodo adoptar una postura especulativa y de desprecio por los hechos y que haga pleno uso de los instrumentos de la razón: es más fácil proclamar la bancarrota de la razón y las limitaciones de la ciencia, anunciando que se está en posesión de fórmulas definitivas, o bien de una peculiar intuición que ahorraría el trabajoso camino de la investigación. Se busca la explicación última de todas las cosas sin atender a las explicaciones provisionales y perfectibles de la ciencia.

¿A qué se deben el descuido de la epistemología y el desdén por la actitud entre nosotros? blioteca. de Letras

\section{"Jorge Puccinelli Converso"}

2. Algunos de los motivos del atraso de la epistemología en Latinoamérica

La epistemología apenas se cultiva en Latinoamerica, y ni siquiera goza en ella de buena reputación. La reputación ambigua de la epistemología en estas tierras parece deberse, entre otros, a los siguientes motivos:

a) En nuestro medio aún no se ha difundido la noticia de que la ciencia se está convirtiendo en el núcleo de la cultura moderna; ni suele estimarse que para filosofar con sentido, rigor y fruto en pleno siglo XX, sea necesario estar al corriente de las grandes conquistas y de los grandes problemas de la ciencia, así como adoptar una actitud científica ante los problemas filosóficos.

b) Durante el último medio siglo han proliferado en Europa, y se han exportado a Latinoamérica, las corrientes irracionalistas. Al negarse la 
razón y exaltarse en su lugar la intuición, al rechazarse el dato fundado y abrazarse el mito, se niega la ciencia, que es un enfoque racional del mundo; y por consiguientes se niega la epistemología, que es la teoría de ese enfoque racional de los hechos materiales y espirituales. En algunos países, el irracionalismo moderno puede interpretase como símbolo de decadencia social; en nuestra América, tan necesitada de razón, esa mercancía importada goza del gran consumo porque es el complemento intelectual del analfabetismo y del atraso técnico y científico. El irracionalista europeo puede tolerar la ciencia a condición de que no conforme la visión del mundo: la Weltanschauung ha de seguir siendo mítica y no científica, pues quien conoce algo acerca del reloj del mundo puede pretender corregir su atraso. Entre nosotros, la prédica irracionalista es menos compleja: es el complemento filosófico de las pretensiones por retornar a la Colonia, a la economía pastoril, a la cultura tradicional de corte predominante histórico-literario. No es dable esperar estímulos a la investigación epistemológica en un medio donde las corrientes oscurantistas gozan de mayor prestigio y poder que las iluministas, en un medio donde se habla más de la pretendida crisis de la ciencia que de sus éxitos.

c) El nivel científico de Latinoamérica es bajo, aunque sube rápidamente. Tenemos un notable déficit de científicos: necesitamos con angustiosa urgencia matemáticos đfísiceos químičos brólogos, psicólogos y sociólogos que contribuyana la explotación racional de nuestras riquezas, a suplir nuestras deficiencias económicas y a superar la etapa de la cultura colonial. ¿Cómo asombrase de que entre los escasos científicos latinoamericanos, recargados de tareas de toda índole, no haya surgido un número ponderable de epistemólogos? Presumiblemente, diez de cada cien científicos suelen tener inquietudes filosóficas, y de estos diez apenas uno se resuelve a encararlas de manera sistemática. En países cuyos científicos puros no llegan a mil, apenas puede esperarse que haya diez epistemólogos.

d) Los filósofos de tipo tradicional no son los últimos escépticos acerca de la utilidad de la epistemología, también la mayoría de los científicos suelen considerarlo pasatiempo de profesores jubilados o de discutidores sin prisa por alcanzar resultados "positivos". Es un hecho que, hasta una veintena de años, casi todos los científicos que abordaban cuestiones filosóficas lo hacían al promediar su carrera o al terminarla. Este fenómeno no se debe solamente a la información unilateral que suele reci- 
bir el especialista: en parte se debe a que, para poder advertir la existencia de problemas filosóficas en el seno mismo de una especialidad científica, y para dedicarse a abordarlos, se necesita adquirir cierta experiencia y despojarse, así sea transitoriamente, de la prisa juvenil que reclama la obtención de resultados inmediatos aun a costa de profundidad de su comprensión. Esta prisa es particularmente justificable entre nosotros: nuestros científi$\cos$, en su mayoría jóvenes, tienen aguda conciencia de que la América Latina no terminará de incorporarse al mundo culto mientras la aventura bélica, política y deportiva gocen en ella de mayor prestigio y protección que esa estupenda aventura intelectual que es la ciencia. Pero tarde o temprano nuestros investigadores advertirán -como las ha ocurrido a todos los científicos de primera línea- que quien encuentra grandes soluciones es quien enfoca los problemas con más amplitud, quien adopta una actitud filosófica ante la ciencia, es decir, quien sitúa al problema dado en su contexto más amplio y está dispuesto a revisar los fundamentos mismos de las teorías o de las técnicas. Así nació la cíencia moderna y así renovó en el curso del último siglo.

Todas estas circunstancias contribuyen a crear un clima poco propicio a la investigación epistemológica. Afortunadamente todas ellas son sólo aspectos de nuestra inmadurez económica-social y cultural, por lo tanto, es dado predecir que häbrản decextinguirsea minedidazge nos desarrollemos.

\section{"Jorge Puccinelli Converso»}

Pero ya es hora de averiguar qué se entiende por epistemología.

\section{Filosofía y ciencia}

Cuando decimos filosofía y ciencia, el signo " $y$ " puede significar la afirmación simultánea de ambos términos, o bien una relación cualquiera entre ellos. Si queremos ser más precisos, debemos recurrir no ya a una conjunción, sino a las preposiciones, por figurar éstas entre los equivalentes lingüísticos de las relaciones lógicas. Juguemos, pues, un rato con las preposiciones, como una de las maneras de averiguar el nombre más correcto de nuestra disciplina.

Empecemos por "de". Si decimos filosofía de la ciencia, damos a entender que se trata del examen filosófico de la ciencia: de sus problemas, métodos, técnicas, estructura lógica, resultados generales, etc. Y así es: de 
todo esto se ocupa la epistemología; pero también de algo más. Probemos “en". Por 'filosofía en la ciencia' -o, más exactamente, 'filosofía de la filosofía en la ciencia'- debiéramos entender, quizá, el estudio de las implicaciones filosóficas de la ciencia, el examen de las categorías e hipótesis que intervienen en la investigación científica o que emergen en las síntesis de sus resultados. Por ejemplo, las categorías de materia, espacio, tiempo, transformación, conexión, ley y causación, e hipótesis tales como "La naturaleza es cognoscible" o "Todos los sucesos son legales". De acuerdo: también de esto se ocupa la epistemología; y sin embargo no basta. ¿Qué nos dirá la expresión 'filosofía desde la ciencia'? Sugiere que se trata de una filosofía que hace pie en la ciencia, que ha sustituido la especulación sin freno por la investigación guiada por el método científico, exigiendo que todo enunciado tenga sentido y que la mayoría de las aseveraciones sean verificables.

Y ¿qué designa 'filosofía con la ciencia'? Esta expresión sugiere ambiguamente- que se trata de una filosofía que acompaña a la ciencia, que no se quede detrás de ella, que no especula sobre el ser y el tiempo al margen de las ciencias que se ocupan de los distintos tipos de ser y de acaecer; que es, en suma, una disciplina que no emplea conocimientos anacrónicos ni trata de forzar puertas ya abiertas. Examinemos, por último, la expresión 'filosofiâpara lactencia'. Sugiēre una filosofía que no se limita a nutrirse de la ciencia sing que aspira a serle útil al señalar, por ejemplo, las diferencias que existen entre la verdad de hecho y la proposición que es verdadera o falsa independientemente de los hechos: será ésta una filosofía que no sólo escarbe los fundamentos de las ciencias para poner en descubierto las hipótesis filosóficas que ellas admiten en un momento dado, sino que además aclare la estructura y función de los sistemas científicos, señalando relaciones y posibilidades inexpresadas.

Todo esto es, en efecto, la epistemología: su filosofía de, en, desde, con y para la ciencia. Para ser equitativa con las cinco preposiciones convengamos en no emplear ninguna de ellas, eligiendo en cambio un término único que posea todos esos significados. ¿Por qué no es epistemología, que etimológicamente significa teoría de la ciencia? $\mathrm{O}$ ¿por qué no metaciencia, que significa ciencia de la ciencia? Cualquiera de estas denominaciones tiene la ventaja de que no reduce el ámbito de la disciplina en cuestión a un capítulo de la teoría del conocimiento, sino que permite abarcar todos los 
aspectos que pueden presentarse en el examen de la ciencia: el lógico, el gnoseológico, y eventualmente el ontológico.

Pero ¿no podríamos proseguir el juego con otras preposiciones, tales como "contra", "sobre", o "bajo"? Es verdad, éstas sirven para caracterizar otras tantas relaciones posibles entre la filosofía y la ciencia: pero veremos que nos son adecuadas. En efecto, "filosofía contra la ciencia" es toda filosofía irracionalista o aquella que, sin serlo del todo, es enemiga del método científico. Aunque escasas y escuetas, hay, sin embargo, filosofía de la ciencia que niegan extensión y valor a la ciencia o la amputan radicalmente, y que además no encaran los problemas de la ciencia de manera científica o siquiera inteligible. Una epistemología que no sea parasitaria, sino que se esfuerce por ser útil a la ciencia, debe empezar por respetarla, aunque no necesariamente con servilismo, ya que la ciencia siempre puede aprender de la crítica filosófica fundada. Quien filosofia contra la ciencia o aun al margen de ella, imita a los escolásticos que rehusaban mirar por el anteojo astrónomo de Galileo.

En cuanto a las preposiciones "sobre" y "bajo", al enlazar los términos "filosofía" y "ciencia" sirven para designar concepciones muy estrechas del lugar y de la función de la epistemología. Si decimos "filosofía sobre la ciencia" sighificamestuma ciencia superioren valor y poder a las ciencias particulares; una scientia rectriz con tales pretensiones de rectoría que los científicos se burlan de ella y con razón, pues la investigación científica no tolera úcases. Por su parte la expresión "filosofía bajo la ciencia" sugiere la posición inversa, de dependencia unilateral de la filosofía respecto de la ciencia: es éste un error que los epistemólogos no cometen en los hechos, aunque a veces lo proclaman como la más excelsa de las virtudes epistemológicas. La filosofía de la ciencia no sólo comporta el examen de los supuestos filosóficos de la investigación científica, sino que tiene derecho a una elaboración creadora en un nivel diferente del científico aunque reposa sobre él: el nivel metacientífico.

No hay pensador más entremetido que el epistemólogo: hoy señala una hipótesis filosófica oculta en un sistema teórico, mañana le discutirá al científico del derecho a usar cierta categoría en determinado contexto, y pasado mañana propondrá una teoría sobre determinada clase de conceptos o de operaciones de la ciencia. La epistemología no está por encima ni por 
debajo de la ciencia: está a la vez en la raíz, en los frutos y en el propio tronco del árbol de la ciencia. Es necesario distinguir los problemas metacientíficos de los científicos, pero no hay por qué inventar un abismo que los separe: acaso no exista problema científico que no suscite problemas filosóficos, ni problema filosófico que pueda abordarse con esperanza de éxito si no es adoptando una actitud científica.

Algunos filósofos carentes de formación científica son culpables de las filosofías de la ciencia que son anticientíficas o por lo menos acientíficas, del mismo modo que los científicos sin formación filosófica suelen ser los creyentes más fervorosos en la existencia de la filosofía de la ciencia, que a menudo es aquella que han aprendido en el libro de epistemología con que se han cruzado. No existe la filosofía de la ciencia en cuanto teoría única: apenas hay intentos, si bien cada vez más serios, por "cientifizar" la epistemología $y$, en general, la filosofía. La situación imperante en este dominio recuerda a la reinante en la física antes de la síntesis newtoniana, o en la biología antes de la síntesis darwiniana: hay muchos resultados dispersos que rompen los moldes caducos de las distintas escuelas, resultados que será preciso ir integrando, cortando para ello las alambradas de púas tendidas entre las escuelas que han hecho contribuciones positivas a la filosofía científica de la ciencia. Quienes emprenden la labor de podar las ramas secas, desarrollar las verdes y coordinarlas en sistemas coherentes Epero transitorios- cumplirán la misión del sinoptikós de Platón Peroaiolol harámyaal margen de la ciencia, no lo harán ignorando el saber moderno, sino que se fundarán sobre él. Toda época ha intentado integrar los conocimientos: nuestra época, la era de la ciencia, intenta integrar conocimientos más o menos verificados, pero no pretende elaborar síntesis cristalizadas.

\section{Disciplinas contiguas a la epistemología}

Si uno de los cometidos del epistemólogo es analizar la estructura lógica de las teorías científicas, entonces la lógica es una de sus herramientas de trabajo. Naturalmente, el epistmólogo se servirá de la lógica de su siglo, sin ser necesariamente un especialista en ella, del mismo modo que el biólogo emplea a la física de su siglo sin ser él mismo físico. Y la lógica de nuestro tiempo -me refiero a la lógica científica-se compone, esencialmente, de la lógica simbólica o logística y de la lógica inductiva o de la inferencia probable. El epistemólogo que ignore la lógica formal moderna 
podrá confundir expresiones del tipo "Sócrates es mortal" con las del tipo "Sócrates fue maestro de Platón". Y quién ignore la existencia de la lógica de la inferencia no demostrativa, no advertirá las diferencias existentes entre el proceso constructivo de una teoría científica y su posterior reordenamiento racional.

Algo similar puede decirse de la semiótica o ciencia de los signos y en particular, de los lenguajes- en la que caben la sintaxis o teoría de las relaciones entre los signos, la semántica o teoría de las relaciones de los signos. Dado que toda ciencia emplea signos, el epistemólogo hará bien en emplear los resultados de la semiótica al analizar el lenguaje de la ciencia. Pero no exageremos. Aunque hay quienes sostienen que la filosofía de la ciencia es sólo lógica de la ciencia o a lo sumo análisis sintáctico y semántico del lenguaje científico; y aunque los formalistas afirman que el epistemólogo sólo debe interesarse por la estructura lógica de las teorías acabadas, es un hecho que las ciencias de la realidad no sólo trabajan con conceptos, sino también con cosas, tanto naturales como artificales. Siendo los actos del científico tan importantes como su pensamiento, la epistemología no debiera limitarse a la lógica y el lenguaje de la ciencia; no debería ser sólo teoría de teorías, sino tambiên teoría de actos, es decir, metodología y no sólo metateoría. Por consiguiente la lógica y la teoría de los signos son herramientas importantes del epistemólogo, peroano las únicas.

\section{"Jorge Puccinelli Converso"}

Muchos epistemólogos hallan tan interesante y fructífero el estudio del proceso de descubrimiento e invención como el de la exposición y justificación de los resultados. Más aún, la historia de la ciencia, y en ella se incluye la más reciente, es nada menos que la proveedora de la materia prima de la epistemología. ¿Por qué ha de interesar la dinámica de la ciencia menos que su estática? Rara vez un interés profundo por las ideas y los actos nos lleva a inquirir sobre su origen y desarrollo. Todavía más: la filiación histórica de unas y otras ayuda a comprenderlos. Así como el estado actual de una especie biológica no se entiende adecuadamente si no es como etapa de un proceso, así tampoco se entiende acabadamente el que hacer científico si sólo se pone atención a sus resultados. Muchos de los esfuerzos del científico del pasado parecen tontos y milagrosos los éxitos del moderno, si no se les ubica en un contexto histórico. Quien sostiene que el epistemólogo sólo debe ocuparse de la estructura lógica y -de haberlo-del fundamento empírico de las teorías acabadas, adopta una actitud fijista que lleva a perificar los resul- 
tados, a olvidar que todos ellos son aproximados y perfectibles. Si se desea estudiar en forma cabal una transformación -y la ciencia es cambiante en grado sumo-es menester adoptar una actitud transformista capaz de captar la dinámica de la averiguación científica.

Otro tanto puede decirse de la historia de la filosofía: a menudo se supone que el epistemólogo nada tiene que aprender de los filósofos del pasado, quienes no harían hecho sino apilar error sobre error. Quien adopta esta actitud arrogante ante sus antecesores se expone a descubrir la pólvora en el mejor de los casos, y la piedra filosofal en el peor. Además, desdeña una de las fuentes de la actividad científica y, a la vez, uno de sus principales resultados, a saber, ciertos principios filosóficos referentes a la realidad en su conjunto, al conocimiento en general, etc. Estos principios participan -habitualmente en forma implícita- de la investigación científica, aunque sólo sea porque intervienen en la visión del mundo del investigador. La adopción de una actitud científica en filosofía, y el tratamiento riguroso de problemas metacientíficos, no implica desdeñar la totalidad de la filosofía tradicional; implica, más bien, abordar íntegramente su problemática, pero ahora sobre la base de los conocimientos científicos actuales y de las técnicas filosóficas actuales. Desde luego el epistemólogo científico desestimará ciertos problemas tradicionales por considerarlos meros enredos verbalos, y concederá a otros problemas muchornerioeimpertancia de la que tuvieron en el pasado. Pererer en compensadión abordará, problemas acerca de cuyo sólo enunciado no podían tener idea sus antecedentes, tales como la estrategia de la experimentación, o las relaciones entre la probabilidad y la frecuencia, o la técnica de la construcción de teorías. El epistemólogo, en suma, no tiene por qué fingir que ha cortado todo vínculo con el pasado, ya que sobre el pasado se encarama, por radicales que sean las novedades que enuncia; si no quiere caer en viejos errores, se esforzará por asimilar el pasado en lugar de desdeñarlo.

El epistemólogo que descuida o desdeña la historia de las ideas científicas y filosóficas, adopta una postura tan altanera y cerrada como la del historiador de la filosofía que ignora la existencia de la filosofía de la ciencia o le confunde con el movimiento negador o retaceador de la ciencia. El fijista que ignora la historia de las ideas suele tomar por definitiva la teoría más reciente, rodeándola de un caparazón escolástico que más tarde podrá dificultar su desarrollo interno y su crítica epistemológica. Así ocurrió con 
la mecánica de Newton, así ocurre con la mecánica cuántica. $\mathrm{Al}$ proceder de esta manera, lejos de ser útil al progreso científico, el epistemólogo fijista podrá llegar a obstaculizarlo. Además el fijista -que se priva nada menos que de contemplar la formación y el desarrollo de los conceptos-suele caer en la tentación de filosofar acerca de una ciencia temporal, perfecta, inexistente, imitando así al metafísico que inventa un "ser" inmutable e inaccesible, allende el acaecer ordinario. La epistemología, en suma, sin confundirse con la historia de las ideas y de las prácticas de la ciencia y de la filosofía, debe hacer uso de ellas, para poder ubicar su objeto en su contexto histórico.

Los empiristas tradicionales buscaban el significado de las ideas en sus raíces psicológicas: creyendo hacer filosofía hacían psicología del conocimiento. Los materialistas vulgares encontraban el significado de las ideas en su correlación con el medionatural y social en que ellas hacen y se desarrollan; creyendo hacer filosofía hacían sociología del conocimiento. La psicología y la sociología del conocimiento son o aspiran a ser ciencias particulares; no forman parte de la epistemología, aunque a menudo se las confunde con ésta, porque las tres hablan sobre la ciencia. Mientras la psicología de la ciencia estudia el correlato psíquico del concepto y del acto del científico, y mientras la sociología de la ciencia estudia la función social de la ciencia y eventualmentela responsabilidađsocial del científico, la filosofía de la ciencia,pop su parte,] secocuparde los aspectos lógicos, gnoseológicos y ontológicos de la ciencia, y no del compartimiento individual o social del investigador científico. Sin embargo, sería miope el epistemólogo que no aprovechase las conclusiones que le brindan la psicología y la sociología del conocimiento, pues ellas le permiten ubicar y comprender más adecuadamente su objeto.

Las disciplinas que hemos mencionado -la epistemología, la lógica la teoría del lenguaje, la historia de la ciencia y de la filosofía y la psicología y la sociología de la ciencia-se esfuerzan por saber qué es el saber. Por consiguiente aunque difieren, distan de ser ajenas entre sí cada una de ellas ilumina una faceta de un mismo objeto; el saber verificable.

\section{Ciencia y humanidades}

Apenas se discute ya que la ciencia es lo que distingue la cultura 
contemporánea de las anteriores. No sólo es el fundamento de la tecnología, que está dando una fisonomía inconfundible a nuestra cultura material, sino que de continuo absorbe disciplinas que otrora fueron artísticas o filosófias: ayer, la antropología, la psicología y la economía; hoy, la sociología y la historia; mañana, quizá la estética y la ética. Además la concepción del mundo del hombre contemporáneo se funda, en medida creciente, sobre los resultados de la ciencia: el dato reemplaza al mito, la teoría a la fantasía, la predicción a la profecía. La cultura social y la personal se tornan, en suma, cada vez más científicas. Hace un siglo, quien ignoraba la Iliada era tildado de ignorante. Hoy lo es, con igual justicia, quien ignora los rudimentos de la física, de la biología, de la economía y de las ciencia formales. Con razón, porque estas disciplinas nos ayudan mejor que Homero a desenvolvernos en la vida moderna; y no sólo son más útiles, sino que también son intelectualmente más ricas.

Semejante actitud no implica desdén para con las artes y las llamadas humanidades; no significa que sea digno de admiración el especialista que permanece insensible a la belleza o que menosprecia la investigación filológica. Lo criticable es que, en el siglo de los mayores avances sociales y de la energía nuclear, se siga sosteniendo que la literatura y la crítica literaria deben seguir siendo el eje de la cultura o por lo menos la base de la formación cultural. Modernícemesel concepte de humanidades y equilibremos los diversos ingredientes de la educación, ofreciendo las posibilidades de una educación integral y actual. Si la vida no es ni debe ser puro goce, y si la cultura no es ni debe limitarse a ser comentario de textos, entonces es preciso que renovemos las ideas acerca del lugar que deben desempeñar las artes y las humanidades en la educación moderna. Sostener que el goce estético y la educación para refinarlo deben ocupar un lugar más importante que la búsqueda de la verdad, de la utilidad y del bien social, no es hoy signo de cultura refinada sino de incultura, de egoísmo, de frivolidad propia de salones victorianos.

¿Cómo es posible seguir sosteniendo que la ciencia y la filosofía de la ciencia son áridas, inhumanas o deshumanizadas, siendo por ello preciso dulcificarlas mediante una dosis de las llamadas humanidades? ¿Acaso las teorías científicas y metacientificas se encuentran en la naturaleza para que pueda tildárselas de inhumanas? ¿No son acaso creaciones humanas, que suelen costar un esfuerzo de imaginación, y de la concepción mayor que de 
la mayoría de las obras literarias y de crítica literaria? ¿Acaso las obras científicas y metacientificas no emplean, además de elementos sensibles y del lenguaje diario, almacenes de experiencias, instrumentales conceptuales y lenguajes enormemente más ricos que los que usa el escritor? Consúltese cualquier revista científica y se advertirá cuán ardorosa -aunque controlada- es la imaginación requerida para inventar una teoría, o para hacer un cálculo aproximado, o para diseñar un instrumento. Ś́lo cree que la ciencia es pobre en conceptos y en imágenes, y que la investigación científica carece de poesía, quien tiene pobres informaciones acerca de la vida de la ciencia. Junto con la filosofía, ella constituye la más rica creación del espíritu. ¿Por qué, entonces, oponer las humanidades a las ciencias, como si éstas fuesen menos humanas que aquéllas, y como si no fuesen precisamente las ciencias las que alcanzan el conocimiento más profundo y adecuado del hombre? Dígase más bien que las ciencias y las llamadas humanidades no son antagónicas sino complementarias, aun reconociendo que en la época contemporánea el centro de la cultura se desplaza de las humanidades a las ciencias.

¿Cómo lograr eficazmente la integración de la ciencia y de las humanidades en la enseñanza universitaria? La solución que suele ofrecerse en algunos países consiste en agregar trabajos de laboratorio al plan de estudios de humanidades, y literatura al plärede estudioß de ciencias. No debe asombrar que esta solución sumista fracase: lo que se agrega se considera materia "blanda", que se tolera y estudia a desgano, sin que deje rastros. No se logra una reorientación de los estudios universitarios y de la mentalidad de los estudiantes con el mero agregado de cursos. Si lo que se busca es una síntesis, debe ensayarse una solución integradora y no aditiva. ¿Por qué no ensayar el cultivo de una actitud filosófica en las ciencia naturales y sociales, y una actitud cientifica en la filosofía y en las llamadas humanidades? No hay por qué buscar la ciencia fuera de las humanidades, cuando lo que se requiere es encararlas en forma científica; ni hay por qué buscar la filosofía fuera de la ciencia, cuando se sabe que ésta posee sustancia filosófica.

La epistemología es terreno particularmente adecuado para advertir la integración de la ciencia, de la filosofía y de las humanidades y para promoverla. La epistemología se ocupa de los fundamentos y procedimientos de todas las ciencias, desde la geología hasta la linguística; la epistemología muestra que la ciencia moderna es una actividad eminentemente espiritual, sirviéndose de la manualidad como de 
un medio. No es difícil mostrarle al estudiante de ciencias que el quehacer científico no es ajeno al espiritual en que se propone edificar sistemas de ideas; que por añadidura, estos sistemas de ideas superan hipótesis filosóficas y conducen al establecimiento de otras; y que toda ciencia plantea, a su vez, arduos problemas a la historia de las ideas, a la sociología y a otras disciplinas que suelen o solían considerarse humanísticas. No es necesario inyectarle humanidades al científico; basta mostrarle que su propia ciencia las incluye o está relacionada con ellas. Exíjasele precisión conceptual al estudiante de ciencias y terminará esforzándose por afilar su lógica y por pulir su expresión literaria; muéstresele el valor intrínseco y social de la ciencia y convénzaselo de que es conveniente la transparencia lógica de los edificios teóricos para saber cómo repararlos o ampliarlos; de esta manera aprenderá a reconocer en su ciencia bastante más que el estudio de una determinada clase de objetos.

No conseguiremos que el científico sea un hombre culto obligándole a estudiar temas que no le interesan. Estimulémosle, en cambio a que advierta la raíz gnoseológica y la armazón lógica de su especialidad; habituémosle a que repare en las conexiones de su especialidad con las demás disciplinas; acostumbrémosle a la idea de que su materia tiene un pasado y una función social, de la que en gran parte depende su futuro. Para conseguir todo esto lo más eficaz son las oportunas acotaciones del propio instructor cie ciencias; pero como en todas partes son contados los profesores de ciencia que poseen información filosófica e históricosócialcconviehe eñsayarcursos especiales de filosofía y de historia de la ciencia.A Ala luz de estas disciplinas, el especialista y el aprendiz de especialista, comprenden que la filosofía y las llamadas humanidades no son del todo exteriores a su materia, y al advertirlo se esforzará por profundizar en estas dimensiones extracientíficas de su especialidad. Así, insensiblemente, se convertirá en un especialista culto. En cambio, del especialista que niega resueltamente que su ciencia tenga relación con la filosofía; de quien se desinteresa totalmente de la estructura lógica; de la evolución histórica o de la función social de su propia especialidad; de éste no puede decirse que sea un hombre culto aun cuando lea novelas o visite exposiciones de pintura. Será tan inculto por desechar todo el saber acerca de lo que a él le interesa saber, que ignorará qué es su propia ciencia.

\section{Los estudios epistemológicos en la formación del científico}

Hay, sin embargo, quienes piensan que, aunque el científico cobre conciencia de las implicaciones y proyecciones no científicas de su propio 
trabajo, no por ello será más eficaz en su especialidad; conceden que será más culto y que por consiguiente vivirá una vida más racional y más rica, pero arguyen que, en cambio, no descubrirá ni inventará más ni mejor, sino el contrario, pues se distraerá con las lecturas y meditaciones marginales a su especialidad. Esta difundida opinión refleja, sin duda, una preocupación responsable por ahorrar desvíos inútiles, pero no ha sido compartida por los grandes maestros del pensamiento científico, y es más bien, típica de quienes toman los instrumentos por fines.

El estudiante de ciencias o el científico que alguna vez dedique una parte de su tiempo a estudios epistemológicos podrá obtener de éstos algunos de los siguientes beneficios.

a) no será prisionero de una filosofía incoherente y adoptada inconscientemente; podrá entonces corregir, sistematizar y enriquecer las opiniones filosóficas que de todas maneras integran su visión del mundo;

b) no confundirá lo que se postula con lo que se deduce, la convención verbal con el dato empírico, la cosa con sus cualidades, el objeto con su conocimiento, la verdad con su criterio y así sucesivamente. Esto le ahorrará buscar demostraciones de definiciones, le impedirá confundir prueba logicomatemática con verificación empiricológica y le ayudará a sopesar el soporte empírico de lasteorías, nōo confundirá materia con masa ni atribuirá masa a toda cantidad de energía; no tomará precedencia ni predictibilidad por causalidad y no reducirá la explicación científica a su especie causal. En general se esforzará por entender los términos que emplea tal como se esforzaron, antes que él, los científicos con mentalidad filosófica que constituyeron la ciencia moderna;

c) se habituará a explicar las suposiciones e hipótesis, lo que le permitirá saber qué es lo que hay que corregir cuando la teoría no concuerda satisfactoriamente con los hechos;

d) se acostumbrará a ordenar sistemáticamente las ideas y a depurar el lenguaje; se habituará, en suma, a buscar la coherencia y la claridad;

e) afilará su bisturí crítico; la meditación epistemológica, al habituar a exigir pruebas, es buen preventivo del dogmatismo;

f) el científico con alguna formación epistemológica podrá mejorar la estrategia de la investigación, al proceder con mayor cuidado en el planteamiento de los experimentos o de los cálculos y en la formulación de la hipótesis, así como en la evaluación de las consecuencias de unas y otras. La 
epistemología ciertamente no ayuda a medir ni a resolver ecuaciones, pero en cambio ayuda a ubicar estas operaciones en el campo de la investigación;

g) su atención se desplazará del resultado al problema, de la receta a la explicación, de la ley empírica a la ley teórica. Ninguna teoría de contenido fáctico le satisfará en forma definitiva: siempre encontrará alguna objeción que hacerle. El estudio de la epistemología, al tornarlo protestón, podrá estimularlo explorar nuevos territorios;

h) la filosofía y la historia de la ciencia le acostumbrarán a considerar la marcha de la ciencia no como un desarrollo meramente aditivo, sino como un proceso en que cada solución plantea nuevos problemas, en que viejas hipótesis desechadas por un motivo pueden volver a cobrar interés por otro motivo, y que cada problema tiene varias capas y, por lo tanto, varios niveles de solución. En cambio, para quien no enfoca la ciencia con una actitud filosófica e histórica, toda fórmula científica es trivial en cuanto a manejarla, y la teoría más reciente es la definitiva, o al menos la penúltima. ¿No hay textos que califican de eyidentes los principios de Newton, y no hay científicos que esperan con impaciencia "la teoría" futura?;

i) se ampliará su horizonte, al enriquecerse el surtido de relaciones lógicas y de posibilidades de interpretación;

j) obrará con cautela cuando tantee terreno nuevo; extremará las exigencias de la verificación, dudará del valor de los datos empíricos que encajen en teorías endebles tö alinenes lospondrá en cuarentena- y no dejará que los detalles le bcultenle esencial. Perpepespor ello perderá coraje; antes bien, sentirá respeto por las teorías consagradas aunque no reverencia por ellas. Así como no hay grande hombre para su valet, tampoco hay teoría intocable para el científico que adopta una actitud filosófica, pues ve a la ciencia, por así decirlo, en pantuflas.

Por todos estos motivos conviene al desarrollo de la ciencia que los instructores de ciencias llamen la atención sobre problemas filosóficos y las raíces históricas de las cuestiones científicas; por los mismos motivos, conviene incluir el estudio de la filosofía y de la historia de la ciencia en los planes de estudio de las diversas ciencias particulares. Con ello no se agregarán conocimientos específicos acerca del mundo, pero sí se facilitará la correcta comprensión, profundización, ordenación y evaluación de dichos conocimientos. El científico o estudiante de ciencias que dedique alguna atención a este género de estudios no se distraerá necesariamente, sino que recibirá estímulos para enfrentar su tarea con mayor profundidad y respon-

\section{HEMEROTECA DE LETRAS}


sabilidad, y hasta con más amor; advertirá que su trabajo es más complejo, más importante y hasta más bello de lo que había creído. Desde luego existe el peligro de que alguno se pase al campo de la epistemología o al de la historia de la ciencia. ¡Enhorabuena si lo hace! ¿No protestamos acaso por la escasez de filósofos e historiadores de la ciencia que conocen el objeto de sus estudios?

\section{El aprendizaje y la enseñanza de la epistemología}

Si no es difícil lograr que el estudiante de ciencias llegue a adoptar una actitud filosófica ante su propia especialidad, es de temer en cambio que, en las condiciones actuales, no sea fácil inducir a los estudiantes de filosofía a que adopten una actitud científica. En primer lugar, debido a la inmadurez de la propia epistemología, la que torna su estudio accidentado. En segundo lugar, porque nuestros estudiantes no han sido preparados para adoptar un actitud científica, sino para lo contrario; salvo excepciones, se les ha inculcado indiferencia y a veces desprecio por la ciencia, y no se les ha dado la formación científica indispensable para abordar con profundidad el estudio de la epistemología.

¿Es probable que existan estudiantes de preceptiva literaria que no sepan leer y escribir? No, porqué sectata de una disciplina que versa sobre el lenguaje escrito y por lotanto los presupone. Y nadie haría caso de un analfabeto que pretendiera enseñarla. En cambio, entre nosotros no provoca asombro ni escándalo el que se enseñe filosofía de la ciencia a estudiantes que, en el mejor de los casos, sólo están equipados con los recursos de las nociones científicas elementales que aprendieron en la escuela secundaria. $\mathrm{Y}$ han sido contados los que, en nuestro medio, se han escandalizado de que hubiese audaces que simularan enseñar filosofía de la ciencia sin haber hecho jamás investigación científica, sin siquiera haber estudiado ciencias en el nivel universitario. Esto no ocupa desde luego, en los centros culturales avanzados, donde la epistemología es enseñada por personas que investigan o han investigado en algún campo de la ciencia, a alumnos que poseen una preparación científica de nivel universitario. No se conoce otra vía para alcanzar un conocimiento adecuado del objeto mismo de la epistemología.

Ni siquiera basta tener nociones sobre la ciencia clásica si se quiere filosofar con provecho sobre la ciencia actual. Para hacer filosofía de la 
ciencia viva, para hacer epistemología útil a la ciencia, para poder detectar y abordar la problemática filosófica suscitada por la investigación científica que se está haciendo ante nuestra vista, es necesario -aunque ciertamente, no es suficiente- tener un conocimiento de primera mano de esa misma ciencia actual. Y esto no le es dado en toda su amplitud a un solo individuo. Por esto la epistemología, como cualquier otra rama del saber y acaso más que otras, es una empresa colectiva, a la que contribuyen numerosos especialistas: filósofos de la lógica, de la física, de la matemática, de la biología, de las ciencias sociohistóricas, etc.

La filosofía de la ciencia que es enseñada por científicos a estudiantes que poseen una formación científica discreta, tiene mucho de farsa. Es hora de que el estudio de la epistemología cobre entre nosotros la seriedad que lo caracteriza en todas partes. Es hora de facilitar, a quienes deseen estudiarla con seriedad, los instrumentos lógicos, semióticos y científicos necesarios. Esta reforma es propugnada entre nosotros, por la novísima Asociación Rioplatense de Lógica y Filosofía Científica. Mientras ella no llegue, será conveniente que alumnos y profesores extrememos la modestia ante las ciencias que hayamos de examinar, tratando de entender sus rudimentos antes de criticarlas.

Para facilitar eBaprendizaje científico previoa sualquier consideración epistemología seria, re contaráconil colaboración de científicos y estudiantes de ciencias, quienes estarán a la disposición de los estudiantes de epistemología y, a su vez, tendrán oportunidad de informarse, por estos últimos, acerca de los problemas tradicionales de la filosofía, con muchos de los cuales entroncan los problemas filosóficos de la actualidad. En cuanto a las numerosas limitaciones del profesor, para subsanarlas, aunque sea en parte, se solicitará el concurso de colegas y especialistas en diversas ramas de la ciencia, para que expongan los problemas filosóficos que han encontrado en el curso de sus investigaciones. De esta manera, cada uno de los participantes del curso aprenderá algo.

El curso de epistemología no tendrá una orientación filosófica definida; su objetivo será facilitar la adquisición de información amplia y objetiva, promover la discusión, y sobre todo, incitar la meditación independiente. Desde luego, el profesor tendrá una orientación definida o la buscará, ya que el pensador sin brújula y sin norte suele carecer de ideas origina- 
les y coherentes, así como del entusiasmo necesario para proseguir la búsqueda y contagiarlo a los demás. No hay filosofía viva sin diálogo y sin cierta parcialidad compatible con la objetividad; al mismo tiempo que se filosofa sobre un tema dado, se dialoga con alguien y se teoriza contra alguien, aun cuando en la exposición final no se trasunten el diálogo ni la polémica.

Se tendrán en cuenta las principales orientaciones filosóficos, sin excluir las anticientificas, aunque sólo sea para analizarlas científicamente. Pero no se tomarán por temas de estudio las escuelas y los autores, sino los "problemas" epistemológicos; ya es hora de abandonar el enfoque exclusiva y predominantemente escolástico e histórico de los problemas filosóficos; es hora de abordarlo sistemáticamente como lo han hecho quienes han dicho algo nuevo. La tarea informativâ quedará, así, subordinada a la labor formativa $\mathrm{o}$, mejor, autoformativa; los autores servirán de peldaños y no de cadenas. Se preferirá el diálogo vivo a la recitación de datos y la discusión inacabada al diálogo definitivo. Se tendrá la pretensión de guardar fidelidad al lema que eligieron los discípulos de uno de los fundadores de la ciencia moderna: "Provando e riprovando".

Se intentará, en suma, adoptar una actitud científica ante los problemas epistemológicoş, conl lasesperanza de que produzcan frutos que convenzan a los científicos de la conyeniencia de encarar filosóficamente la ciencia y que persuadan a los filósofos de que la filosofía rigurosa y profunda no es un género literario sino una ciencia. 